التربية والسلوك في الطريقة الثاذلية

التربية والسلوك في الطريقة الثاذلية.

الباحث/ محمد بسيونى حسني النواوي

لارجة الدكتوراة قسم دراسات ويحوث الديانات

معهد الاراسات والبحوث الآسيوية قسم دراسات ويحوث الأديان

\title{
جامعة الزقازيث
}

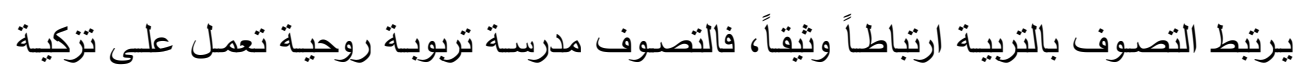

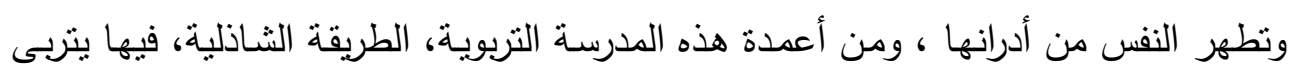

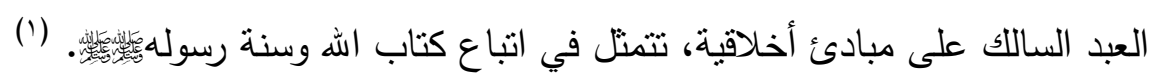

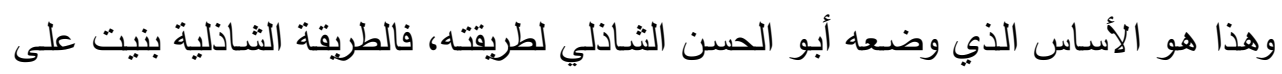
عدة أسس وهذه الأسس هي التي مكنت الطريقة من الانتشـار والذيوع عبر مئات السنين وتتلخص في : إتباع الكتاب والسـنة ،وترك المعاصسي ، وفعل الواجبات ، وترك التدبير

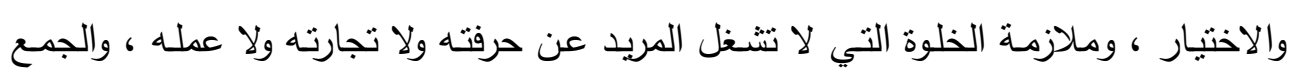

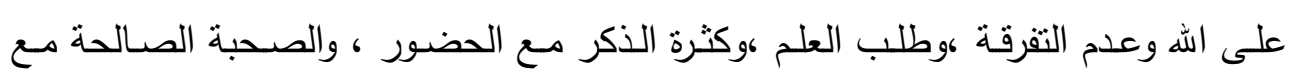

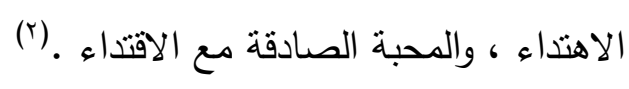
أصول وتعاليم الطريقة الثاذلية: يقول بـن زروق: تتمثنل أصـول الطريقـة الثـاذلية في تعـاليم خمسـة: تقـوى الله في السـر

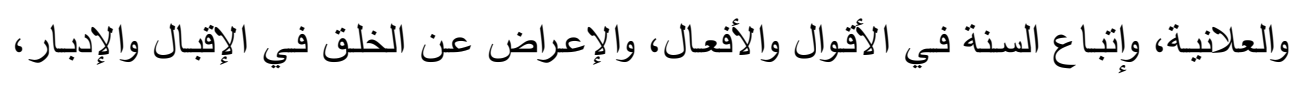
والرضا عن الهه في القليل والكثير، والرجوع إلى الله تعالى في السراء والضراء.فتحقيق التقوى الته

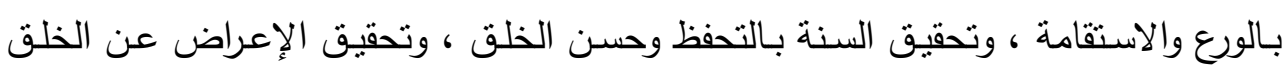

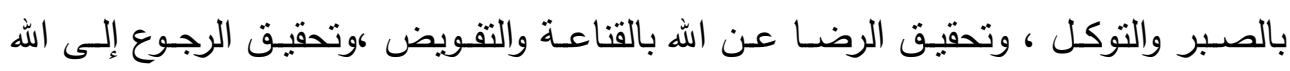

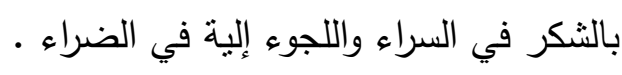
ويضيف : وأصول ذللك كله خمسة : علو الهمة ، وحفظ الحرمة ، وحسن الخدمة ، ونفوذ العزيمـة ،وتعظيم النعمـة ، فمـن علت همته ارتفعت رتبتهه، ومـن حفظ حرمـة الله حفظ الله

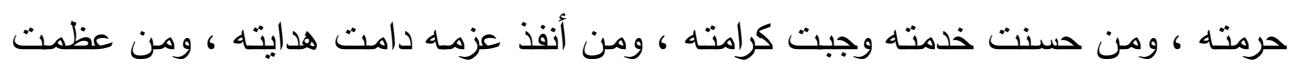
النعمة في عينه شكرها، ومن شكرها استوجب المزيد من المنعم. 
وأصول المعاملات خمسة : طلب العلم للقبام بالأمر ، وصحبة المشايخ والإخوان للتبصر النور

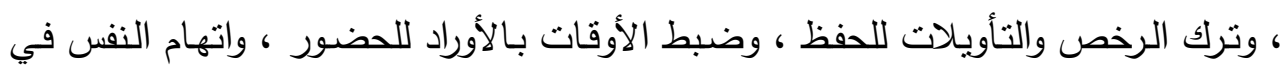

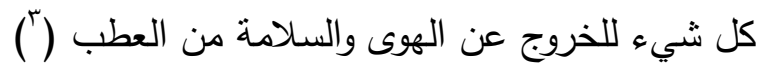

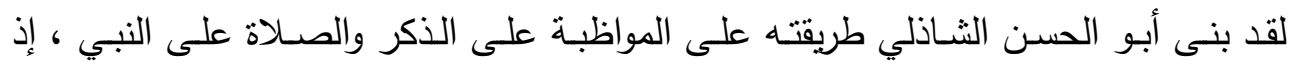
بوسع الساللك أن يصل إلى درجة القطبانية بـلا واسطة كما لم يشترط اتخاذ زاوية أو رباط

\section{ويقوم منهج التربية في المدرسة الشاذلية على عدة أمور مهمة هي:}

يوضح أبو الحسن طريق السلامة فيقول: إذا أردت السـلامة من الغرور فاخلص العمل لله ،

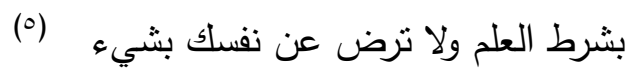
التويـة : يقول أبو الحسن : عليك بالاستغفار ، وإن لم يكن هناك ذنب ، واعنبر باستغفار

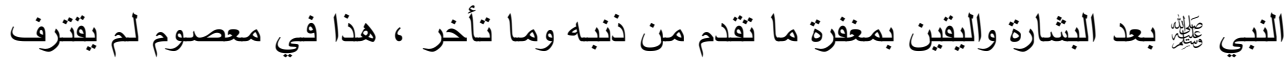
ذنبا قط وتتزه عن ذللك ، فما ظنك بمن لا يخلو عن العيب والذنب في وقت من الأوقات ؟

النيـة: يقول أبو الحسن الثـاذلي : إن للنية محلا ووقتا وكيفية ـ ويوجها أبو الحسن المريد بقوله : حسن نيتك فيما بينك وبين اله ، بتوجـه القلب بـالتعظيم لله ، والتعظيم لأمـر الله ،

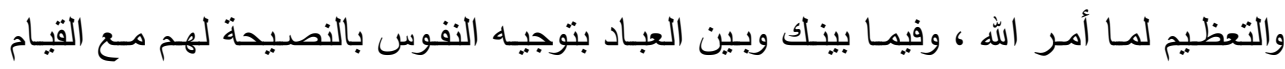

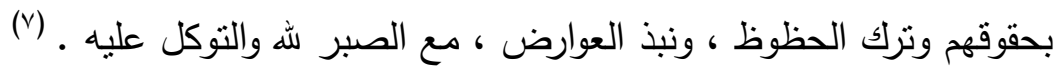
الطريـق إلى الله: يوضـح أبو الحسن الثـاذلي لمريديه الطريق إلى الله بقوله: طريق القصد إلى الله: أوله: الذكر ، وبسـاطه العمل الصـالح ، وثمرتـه النور ، وثانيـه: التفكير وبسـاطه الصبر ، وثمرته العلم ، والثالث: الفقر في الله ، وبساطه الثكر ، وثمرته المزيد منه ، وأما

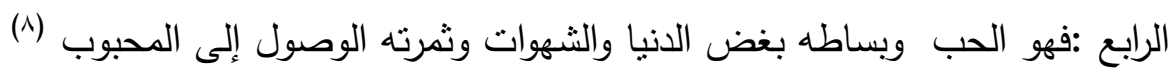

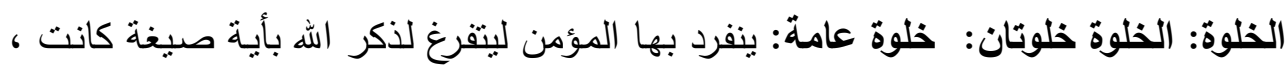
أو لتلاوة القران أو محاسبة النفس. 
التربية والسلوك في الطريقة الثـاذلية

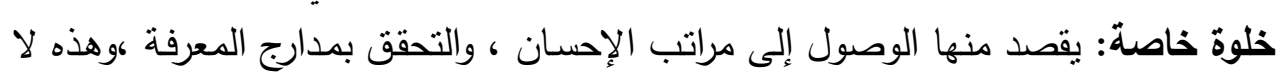
تكون إلا بإثـراف مرشـد مـأذون ،يلقن المريد الذكر الخـاص بـه ويكون على صـلة دائمـة الإنة به،ليزيل عنه الشكوك ويرفع عنه الحجب والأوهام (9) .

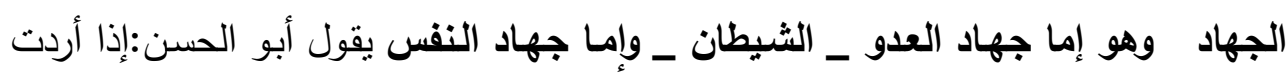

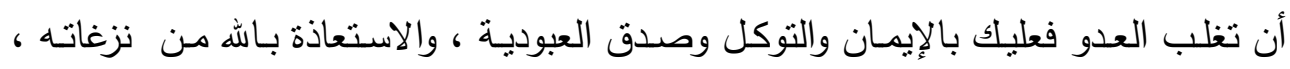

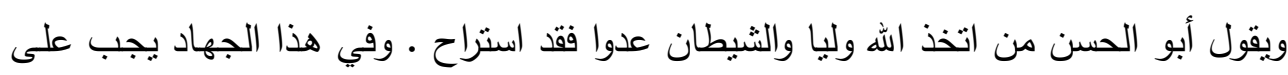
المريد، اللجوء والافتقار دائما إلى الله فيقول دائما سلمني، نجني خلصني أنقذني. (·) النفس :يقول أبو الحسن : إذا أردت الجهاد بـالنفس فاحكم عليها بـالعلم في كل حركة ،

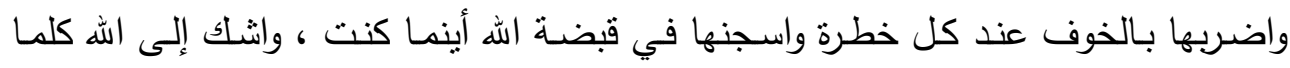

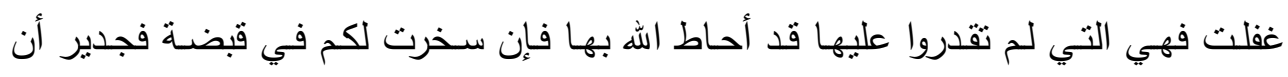
تذكروا نعمة الله عليكم وتقولوا: سبحان الذي سخر لنا هذا وما كنا له مقرنين) الزخرف سا

الانيا: الناس أمام الدنيا رجلان ، رجل أخذ منها بمنهج الله ما يحتاجه في حياته ، ويحقق

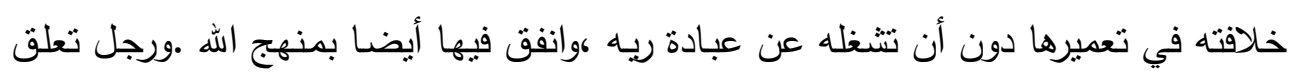

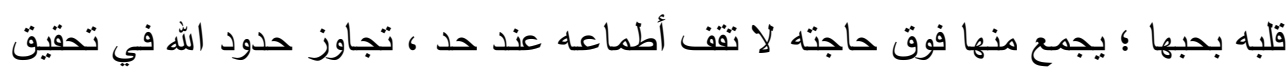
أغراضه ومراميه .فالأول عمر دنياه وأخراه ،والثاني خسر نفسه ، وعمر دنياه وخرب آخرته.

العبوديـةة: العبوديـة لا تكـــن إلا لله، والخـروج مـن الـرق إلـى الحربـة، وطلب الغنـى عن

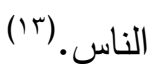

الطاعـات: وهي ثمرة العبوديـة،إن الذي أكرمهـ الله بالعبوديـة يؤدي الطاعات كلها في وقتها

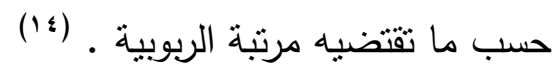

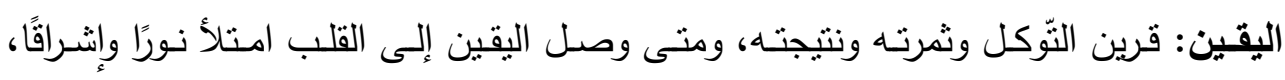

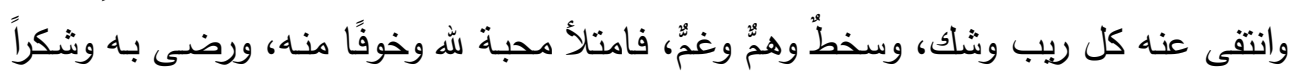

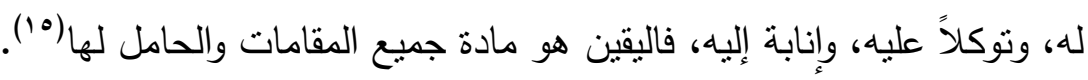




\section{الباحث/ محمد بسيونى حسني النواوي}

التوكل: التوكل تمام اليقين باله تعالى ، لأن التوكل لا يكون إلا بحسن الظن باله، والتقة بما

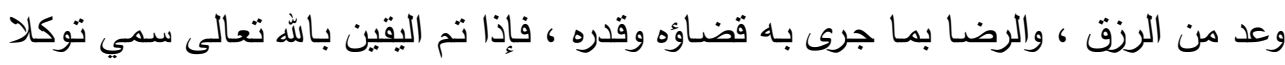

الرضـا: يقول أبو الحسن: ألق بنفسك على بـاب الرضـا، وانخلع عن عزائمك وإرادتك.حتى

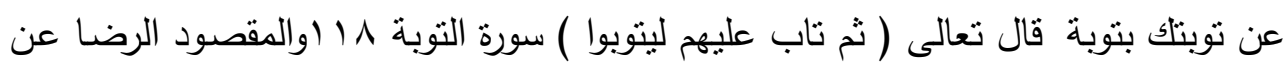
الله وعن قضائه. (Iv)

الورع : يقول أبو الحسن : الورع نعم الطربق لمن عجل ميراثه ، وأجل ثوابه ، فقد انتهى بهم الورع إلى الأخذ من الله وعن الهه والقول بـالهه والعمل لله وبـاله، على البينـة الواضـحة والبصيرة الفائقة ، وهم في عموم أوقاتهم وسائر أحوالهم لا يدبرون ولا يختارون ولا يرتحلون

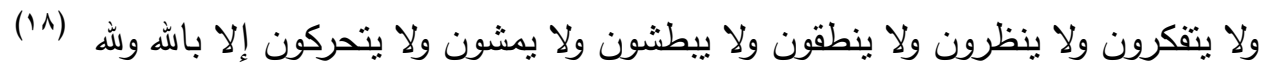
الأكر: الركن الأساسي في الطريق الصوفي بصفة عامة، وبه يترقى المريد ويتجاوز العقبات والمراحل والذكر بـاب الخيرات، والعمدة في طريق الله، وهو الأصـل الجـامع، وهو الركن

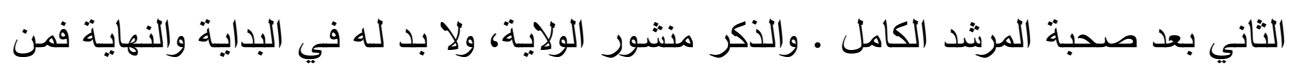

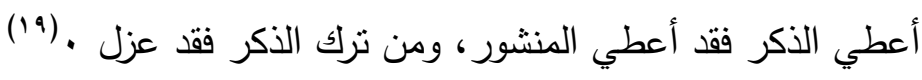

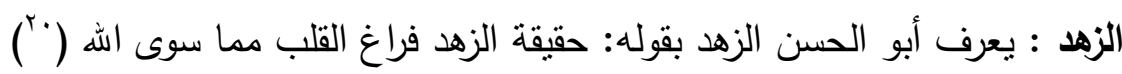

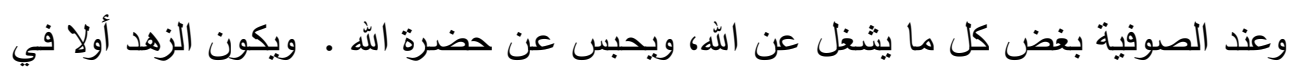

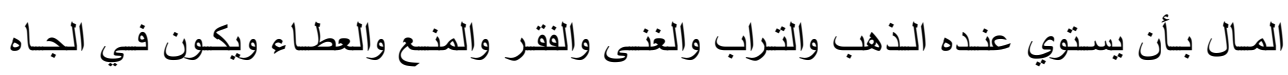

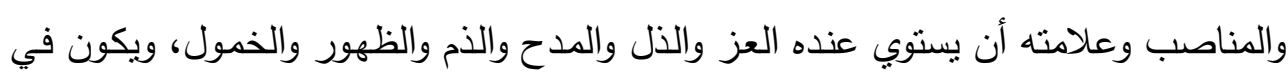

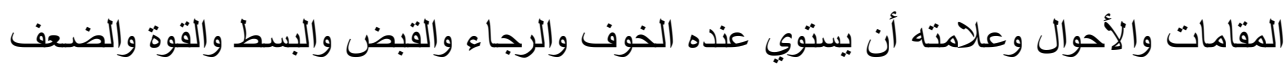

(r) $\ldots$

المحبة : يصف أبو الحسن المحبة بأنها بساط الكرامة، وهي أصل في الإفهام، فمن أحب الله فهم عنه كل شيء والمحبة هي الموصلة إلى طريق الله يقول أبو الحسن الثاذلي:

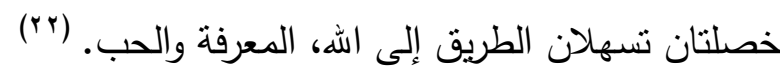
وعلى هذه الأسس بنيت الطريقة الثاذلية 
التربية والسلوك في الطريقة الشاذلية

منهج أبو الحسن الثاذلي في تربية المريدين

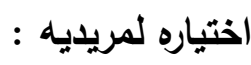

كانت القاعدة عند أبي الحسن الثاذلي ،وأبي العباس المرسيهوبن عطاء الله في قبولهم

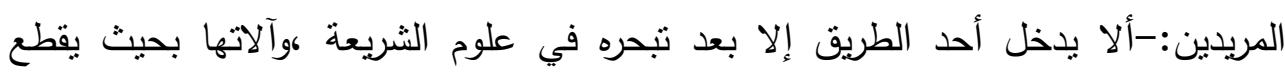

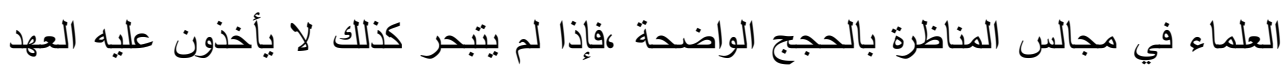

كان الثاذلي إذا جاءه الرجل ليلازمه الطريق سأله عن علمه،فإن لم يكن صاحب علم ، قال

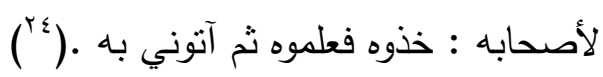

الأمر بالتمكك بالكتاب والسنة

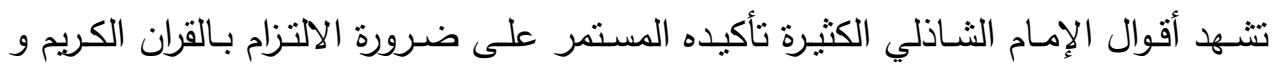

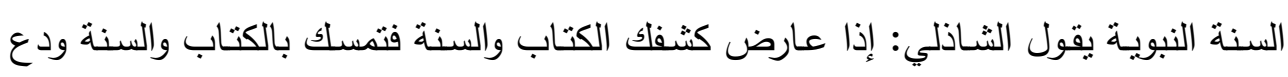

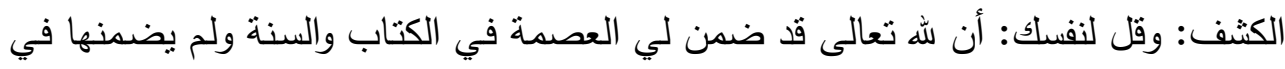

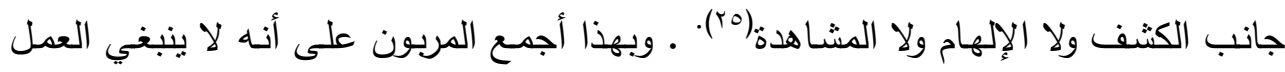

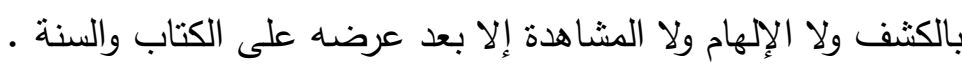

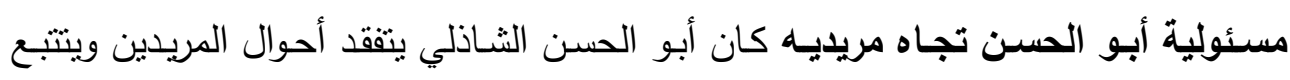

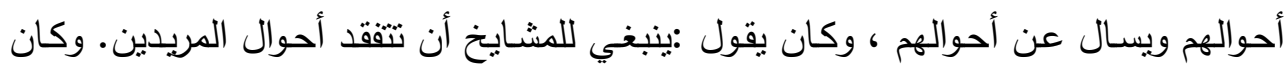

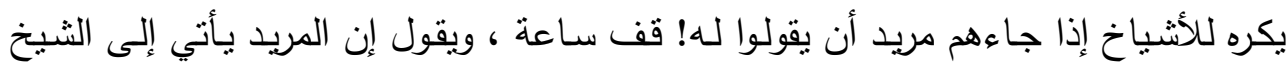

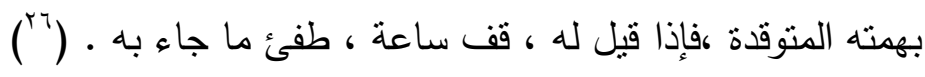

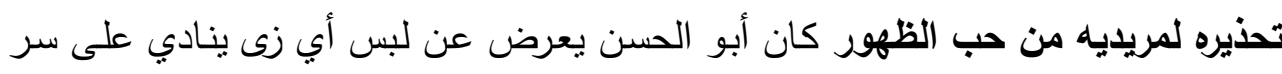

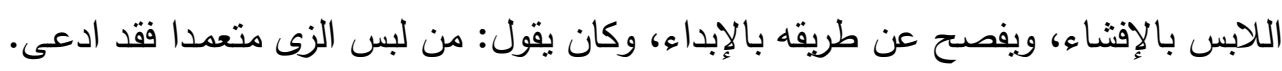

تحذيره لمريديه من التعطل وترك العمل كان أبو الحسن الثاذلي يكره من المريد أن يكون متعطلا أو أن يسأل الناس. وكان ئنس يقول:

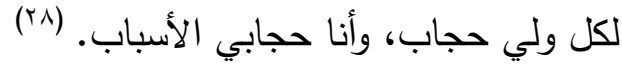


كان أبو الحسن يشارك في الزرع، والحرث، والحصـاد، ويربي الثيران، فهو لم يدعو إلى لـى

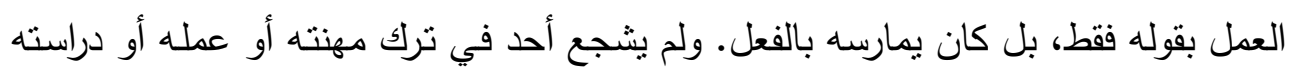

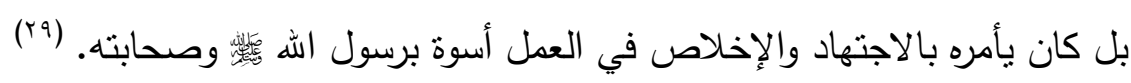

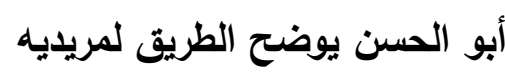

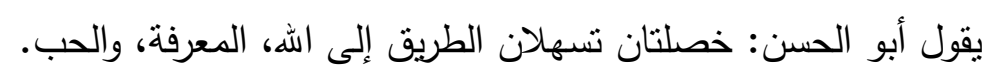

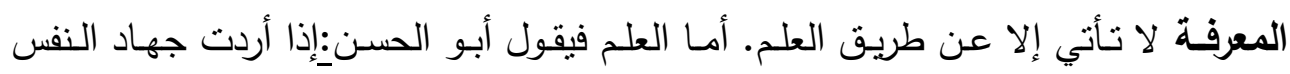
فاحكم عليها بالعلم في كل حركة، واصرفها بالخوف عند كل خطرة، واسجنها في قبضـة الله أينما كنت، واشك عجزك إلى اله كلما غفلت. أمـا الحب فهو أسـاس الطريقة الثـاذلية. يقول الإمـام الثـاذلي: إننا ننظر إلى الله بيصر

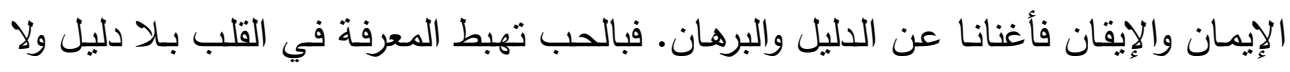
برهان.. ويؤكد أبو الحسن ذلك بقوله موت النفس بالعلم والمعرفة والاقتداء بالكتاب والسنة

أبو الحسن الشاذلي لا يمنع مريده بالاتصال بغيره من المشايخ

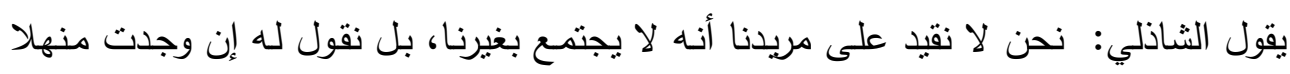

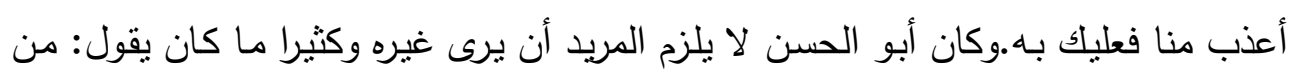

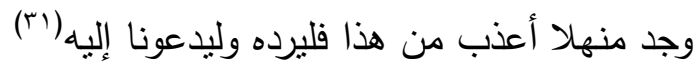

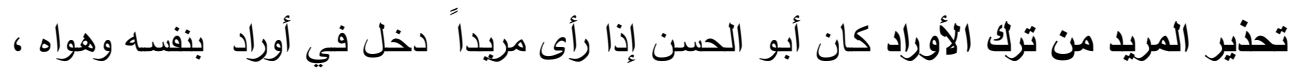

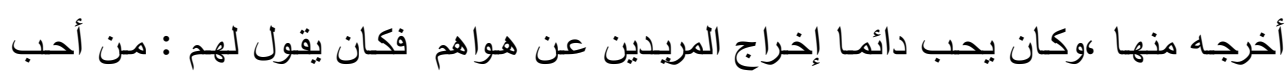
الظهور فهو عبد الظهور ، ومن أحب الخفاء فهو عبد الخفاء ، ومن كان عبدا لله ، فسواء هوناء عليه أظهره الهه أو أخفاه (rr)

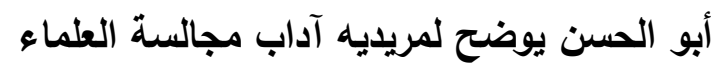

يقول أبو الحسن: إذا جالست العلماء فلا تحدثهم إلا بالعلوم المنقولة والروايات الصحيحة، وإما أن تفيدهم، وإما أن تستقيد منهم، وذلك في غاية الربح منهم، وإذا جالست العباد والزهاد فاجلس معهم على بساط الزهد والعبادة.( (r) ) .

rV. مجلة بحوث كلية الآداب 
التربية والسلوك في الطريقة الشاذلية

الكرامة الحقيقية عند أبو الحسن

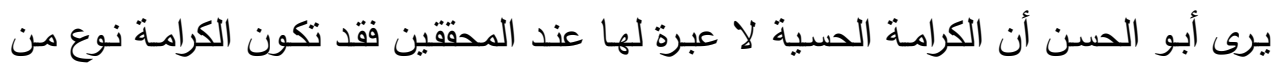
الاستدراج ، فالكرامة الحقيقية عند أبو الحسن هي حصول الاستقامة والوصول إلى كمالها ،

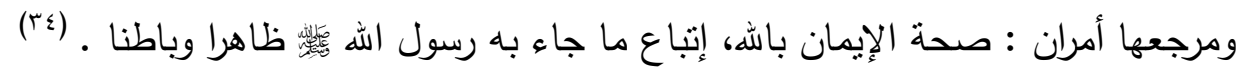
دعوته لاختيار الأصحاب والرفاق. من أهم ركائز الطريق الصوفي الصحبة فنجد أنهم دائما يأمرون باختيار الرفقاء في السير

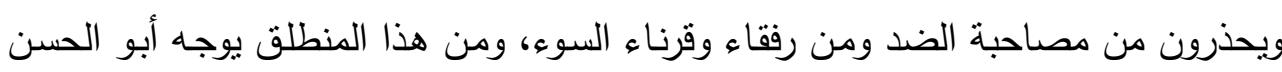
مريديه إلى اختيار الرفقاء فيقول: لا تصحب من لا يُنِفيُك حاله ، ولا بدلك على الله مقاله

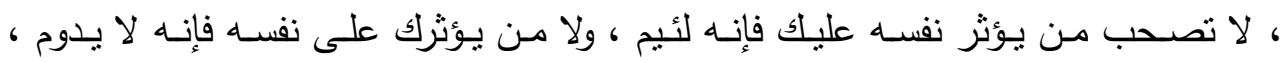
واصحب من إذا ذكر ذكر الله ... وليكن قصدك الله.(ro) دعوته لقضاء مصالح الناس كان مما يميز شخصية الثاذلي سعيه للخير ولقضاء مصالح الناس. يقول ابن عطاء الهه السكندري: أخبرني بعض أصحابنا قال: استشفع طالب بالثيخ أبا الحسن إلى القاضي تاجي الدين ابن بنت الأعز أن يزاد على مرتبه فذهب الثيخ إليه فأكبر القاضي تاج الدين مجيئه

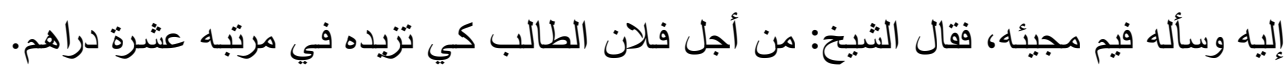
فقال القاضي: يا سيدي هذا له في المكان الفلاني كذا، وفي المكان الفلاني كذا وكذا... فقال

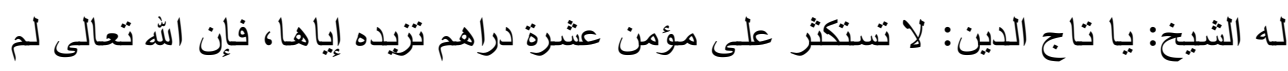
يقنع المؤمن بالجنة جزاء حتى زاده النظر إلى وجهه الكريم(؟r). دعوته إلى التسامح مع من أساء وعدم الدعاء عليه. لقد قاسى أبو الحسن في طريقة الكتير من المصاعب وتعرض للمكائد والدسائس في كل مكان يذهب إليه، فكان يفوض أمره دائمـا لله فينصره على أعدائه، ولم يشـخل نفسـه بتلك فئك الدسائس والمؤامرات حتى يتفرغ لاعوته فكان النصر والتأييد من عند الهه وفي هذا الصدد

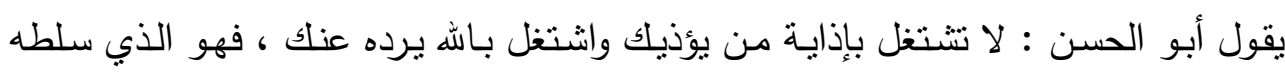

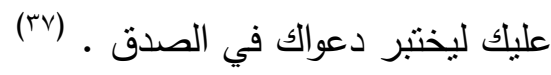




$$
\text { الباحث/ محمد بسيونى حسني النواوي }
$$

التحذير من الانوب والمعاصي .يقول أبو الحسن إياك والوقوع في المعصية المرة بعد المرة؛ فان من تعدى حدود الله فهو الظالم، والظالم لا يكون إماما، ومن ترك المعاصي، وصبر على ما ابتلاه اله، وأيقن بوعد الله ووعيده فهو الإمام وان قلت أنباعه.

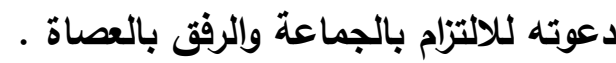

كان الصـوفية على مر الزمان من دعاة الألفـة والمحبـة وكان لهم دور كبير في استقرار المجتمعـات التي تواجدوا فيها ومـن خـلال ذلك نجد أبـو الحسـن يدعو مريديـه بـالالتزام

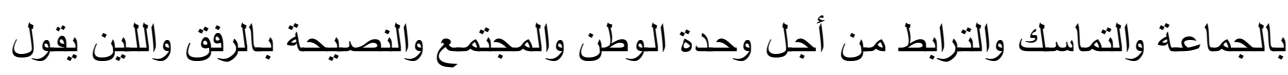

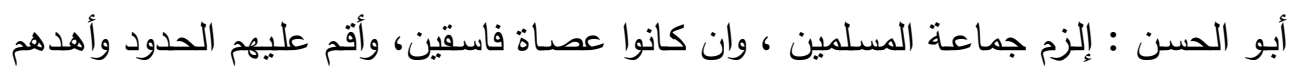

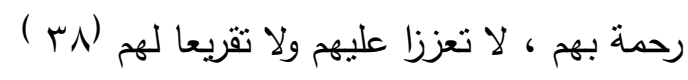

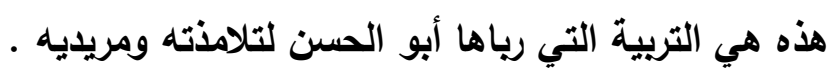

لقد ربى أبو الحسن أنباعه ومريديه بصورة علمية ايجابية. ربى أجيالا كانوا كتبه ، إذ نشروا

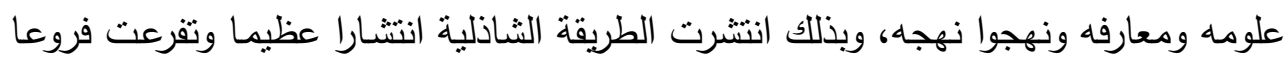
شتى ليس في مصر وحدها بل في جميع بقاع العالم الإسلامي.

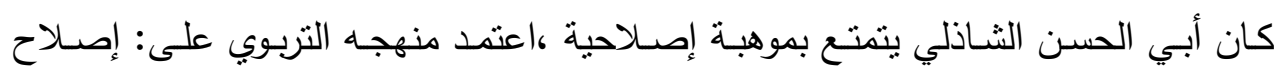

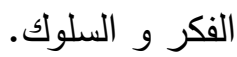

استطاع أبو الحسن أن ينجح في علمه الإصـلاحي والتربوي ، لا بتوجهاته وأقواله فحسب، بل بعمله وسلوكه، حيث انعكست دعوته الإصلاحية والتربوية ، على فعله، وحاله، ومقاله..

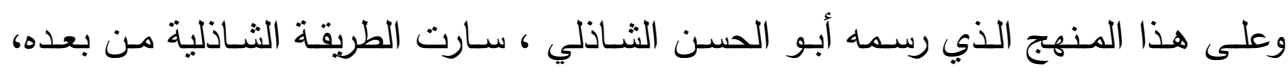

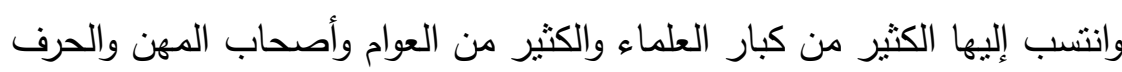
اعتمد المنهج التربوي عند أبو الحسن الثاذلي على القرآن الكريم والسنة النبوية المشرفة واءية وبذلك ابتعد الثـاذلي عن التصوف الفلسفي ونظرياته ،ولم يهنم بالكرامات وخوارق العادات إذ أن الكرامة الحقيقية عنده هي حصول الاستقامة . 
التربية والسلوك في الطريقة الشاذلية

( ( ) حسن الثـرقاوي ، معجم ألفاظ الصـوفية ، مؤسسـة مختار للنشـر والتوزيـع ، مصـر ،

$$
\text { r. (19NV }
$$

(') محمد رمضـان محمد سعيد ، الآداب الصـوفية لمريدي الطريقة الثـاذلية، دار بورسعيد

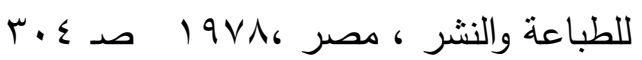
(r)سعيد أبو الإسعاد، نسق الخطاب على تحفة الأحباب، هذا هو الثـاذلي أبو الحسن

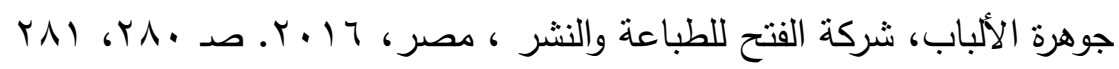
(ع )عبد المغيث بصسير المغربسي تـاريخ الطريقـة الثـاذلية وتطورهـا ، ،دار اقرأ ، سـوريا ،

$$
r \cdot r \cdot r
$$

(0)محمد رمضـان محمد سعيد ، الآداب الصـوفية لمريدي الطريقة الثـاذلية، مرجع سـابق، صد

(7)(أبى علي الحسن بن القاسم الكوهن المغربي الفاسي ، طبقات الثـاذلية الكبرى المسمى جامع الكرامات العلية في طبقات السادة النشاذلية ، تحقيق محمود الجمال ، المكتبة التوفيقية ، مصر ،د ت، صد

(ع) الحبد اليم محمود ،المدرسـة الثـاذلية وإمامها أبو الحسن الثـاذلي ،دار الكتب الحديثة (T)

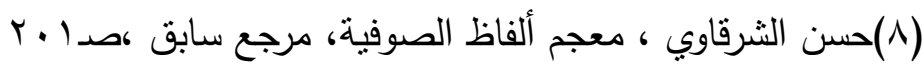

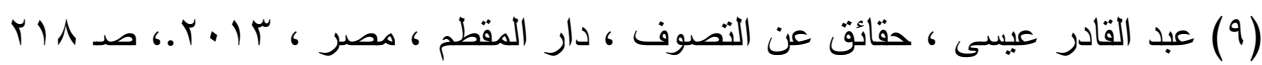

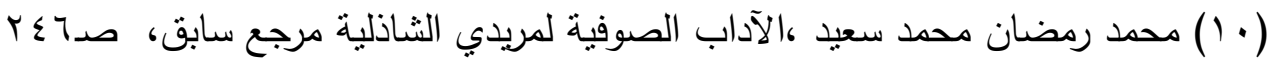

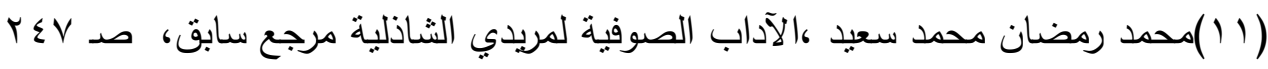
(r ( ) يحيى بن معاذ الرازي ، جواهر التصوف ، شرح سعيد هارون عاشور ، مكتبة الآداب

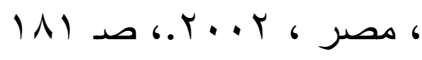


( r ( )محمد القاوقجي البدر المنير على حزب الثـاذلي الكبير ، المطبعة النصيرية ، مصر ، VO

( ( ) (أحمد حسن ريدادة ، أعـام في التراث الصـوفي من آل بيت الرسـول ، دار الكتاب

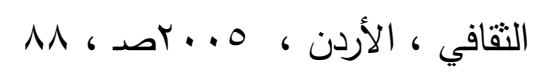

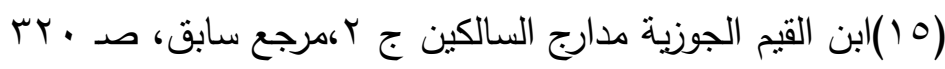

(7 ( )محمد بن أبي يكر شمس الدين الرازي،حدائق الحقائق ، تحقيق ،سعيد عبد الفتاح ،

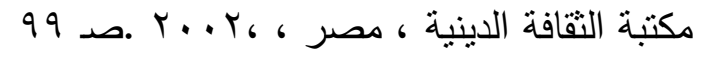

( V ( أحمد أبو كف ، أعـام التصوف الإسـلامي ، دار التعاون للطباعة والنشر ، مصر ،

$$
09 \text { صـ 199 }
$$

(1 ( ) أحمد حسن ريدادة ،أعلام غي التصوف الإسلامي، مرجع سابق ، صـ ؟0 (9 ()أحمد بن عجيبة ، إيقاظ الهمم في شرح الحكم ، مكتبة زهران ، مصر ، 990 ا ـ صـ

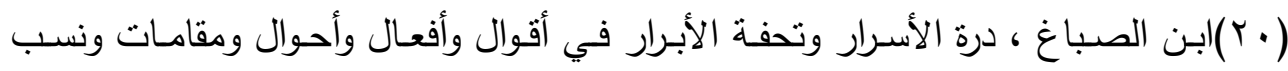
وكرامـات وأذكـار ودعـوات سيدي أبـو الحسـن الثـاذلي المكتبـة الأزهريـة للتـراث ، مصـر ، 111

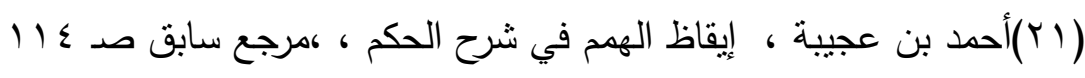

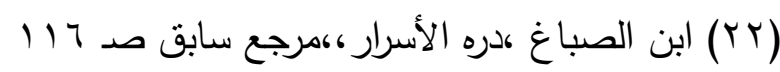

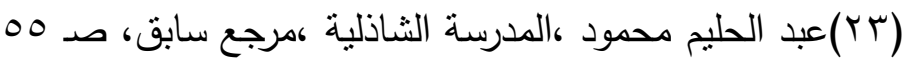

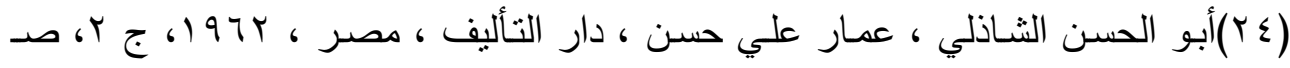

(ro) طله عبد الباقي سرور ، التصـوف الإسـلامي والإمـام الثـعراني ،مكتبة ومطبعة نهضـة

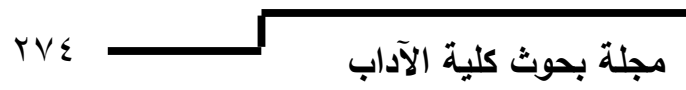


التربية والسلوك في الطريقة الشاذلية

مصر ، صدع 9

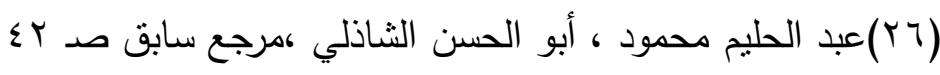

(الموسوعة الصـوفية ،أعلام التصـوف والمنكرين عليه ،والطرق الصوفية ،عبد المنعم

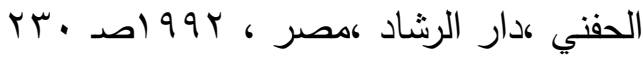

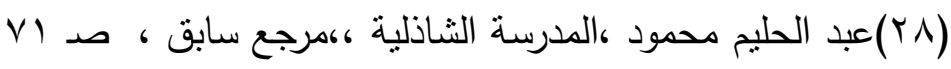

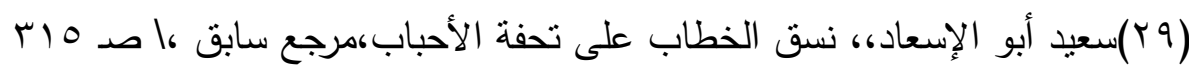

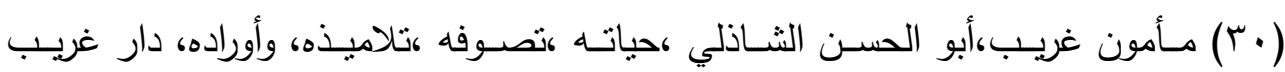

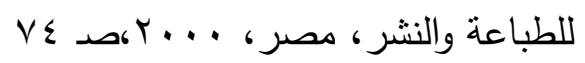

(اسج)حامد إبراهيم صقر ، نور التحقيق في صحة أعمال الطريق ،مرجع سابق ، صـ بسا

(r) عبد الحليم محمود ،أبو الحسن الثاذلي ،الصوفي المجاهد والعارف باله ، صـ سع

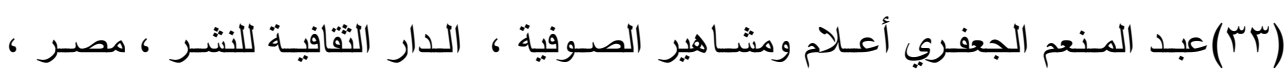

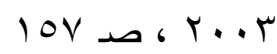

(؟)مأمون غريب، أبو الحسن الثاذلي ،حياته ،تصوفه ،تلاميذه ،مرجع سابق ، صـ 19

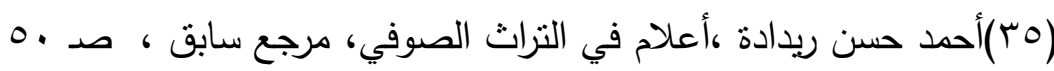

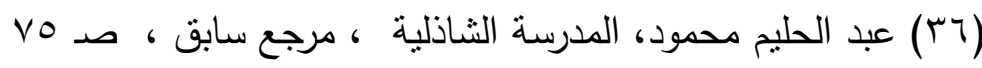

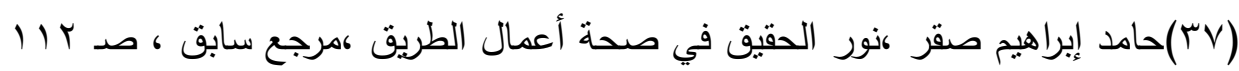
(r^)أبى علي الحسن بن محمد بن القاسم الكوهن المغربي الفاسي ، طبقات الثاذلية الكبرى، مرجع سابق ، ص 